\title{
Bizarre Foreign Objects in the Genital Tract-Our Experience and Review of Literature
}

\author{
Sankhwar Pushplata*, Misra Devyani, Jaiswar Shyam Pyari, Sujata Deo \\ Department of Obstetrics and Gynaecology, K. G. Medical University, Lucknow, India \\ Email: sankhwar pushpa@yahoo.com
}

Received 1 April 2014; revised 1 May 2014; accepted 8 May 2014

Copyright (C) 2014 by authors and Scientific Research Publishing Inc.

This work is licensed under the Creative Commons Attribution International License (CC BY). http://creativecommons.org/licenses/by/4.0/

c) (i) Open Access

\begin{abstract}
Foreign objects in the genital tract are commonly encountered by clinicians in all age groups. Patients may or may not be aware of its presence in the body. Usually presenting as offensive vaginal discharge, rare misplacement of these objects may result in fatal complications. Detailed history and clinical examination are central to diagnosis although imaging modalities may be required in misplaced objects. Proper management can prevent morbidity and mortality resulting from complications. Presented here is a series of three cases where patients presenting with varied complaints were diagnosed with genital foreign bodies and managed.
\end{abstract}

\section{Keywords}

Foreign Bodies, Vaginal Discharge, Post Coital Bleeding

\section{Introduction}

Foreign objects in the genital tract may be placed accidentally or on purpose.

Prolonged retention of these objects may result in excessive offensive vaginal discharge. Such cases are reported more commonly in aged women with altered awareness or memory loss and those involved in substance abuse. The incident is also high in pediatric age group and has at times been used to conceal child abuse. Commonly foreign bodies retrieved from the vagina include tampons, pins, buttons, seeds, toy parts, objects used in foreplay, and pessaries forgotten in the vagina or even illicit drugs for trafficking. We report a series of three cases where bizarre objects were recovered from the uterus and vagina without the patients' being aware of their presence inside the body.

${ }^{*}$ Corresponding author. 


\section{Case Reports}

1) An eighty-year-old multipara (2 Alive), postmenopausal woman presented with blood-stained foul smelling vaginal discharge often for past 3 months. She was brought to the hospital chiefly for her febrile ill-health with vaginal discharge. Her obstetric history included five full-term home deliveries in squatting position without medical assistance. Her last delivery was 40 years back. A pelvic ultrasound was advised by a general practitioner and it showed a ring shaped foreign body in the vaginal area without any other abnormality. On general examination, she was febrile, ill-looking but had stable vitals with generalized debility. Per speculum examination revealed an atrophic shortened vagina with a rim of pessary in the mid vagina, purulent and blood stained discharge with inflammation and granulation over the embedded pessary in the vagina (Figure 1). On per vaginal examination, pessary was felt in the mid vagina. The examining finger could be negotiated through the rim to the cervix where it was felt embedded in the cervical tissue. The patient was not able to recollect the use of vaginal pessary in the past.

Intravenous broad spectrum antibiotics were given. She was re-examined under anesthesia and a medium sized rubber ring pessary was removed by incising the cervix vertically. Cervical biopsy was also done which showed granulation tissue with chronic inflammation. Vagina was irrigated with povidone-iodine and vaginal packing done. The pack was removed after twelve hours. There was no bleeding from the vagina. She was given a course of antibiotics for five more days and was discharged in satisfactory condition.

2) A twenty-one-yea-old Nulliparous lady married for 6 months, presented to the gynecology OPD with complaints of post coital bleeding and foul smelling discharge per vagina. On further questioning, history revealed that the patient had been sexually assaulted about a year back by her relative at home and no lawful complaint was lodged regarding the incident and no medical examination was done at that time. On further inquiry, she revealed that something was inserted inside her vagina at the time of assault.

On admission, general examination revealed febrile morbidity. Speculum examination revealed part of a red colored plastic foreign object embedded in the upper vagina. On per vaginal examination, a hard object with sharp rounded edges was made out, embedded deep in the upper part of vagina with blood staining of the examining finger. She was started on broad spectrum antibiotics and all relevant investigations including urine and vaginal cultures were sent. The reports revealed a TLC of 16300/cu.mm with raised neutrophils. Ultrasound examination of the pelvis revealed a foreign body with rounded edges measuring $5 \times 4 \mathrm{~cm}$ posterior to uterus.

Patient was taken up for examination under anesthesia and the foreign object was removed. To our surprise, it was the front part of a red colored flash light with plastic body (Figure 2).The patient was discharged after completion of antibiotic course in satisfactory condition. In follow-up, the anatomy of cervix and vagina appeared normal and healthy.

3) A seventy-year-old grand multipara lady came to the gynecology OPD with complaints of something coming out of the vagina since 6 years and difficulty in passing urine and stools with complaint of occasional blood stained discharge for the last 4 months. She had all full-term vaginal deliveries at home which were unsupervised. Local examination showed cervix lying around 3 inches outside the introitus with cystocele and rectocele. Overlying mucosa was dry and keratinised. There was no evidence of decubitus ulcer. Palpation revealed atrophic uterus with procidentia. The patient was investigated thoroughly and taken up for vaginal hysterectomy. The surgery was uneventful. On cut section the uterus showed presence of a dead cricket inside the uterine cavity with otherwise normal appearing atrophic uterus (Figure 3). The patient was discharged after completing antibiotic course in satisfactory condition.

\section{Discussion}

Foreign objects are commonly recovered from vagina of young girls who may insert these while exploring their body. Often these include pen caps, toys and toilet paper [1] [2]. Small children are usually unable to narrate how or when the object was inserted and this may delay parents seeking help for complaints of pain or vaginal discharge. At times, the object may be placed deep inside and may be missed on local examination or even a rectal examination [3]. There have been reports of vaginal foreign bodies which were eventually found to be cases of sexual abuse [4]. Therefore, one should always exclude the possibility of abuse in such cases when dealing with children who present with vaginal discharge.

Among adults, commonly recovered foreign objects from the genital tract include pessaries, contraceptive devices, tampons, seeds, surgical instruments (often forgotten) and sexual aids retained inadvertently [5] whereas 


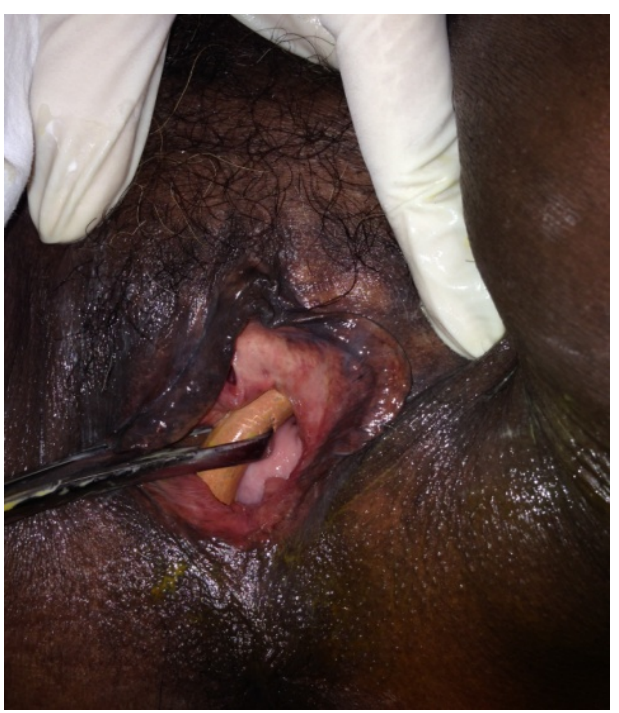

Figure 1. Photograph showing ring pessary in the vagina embedded into the cervix.

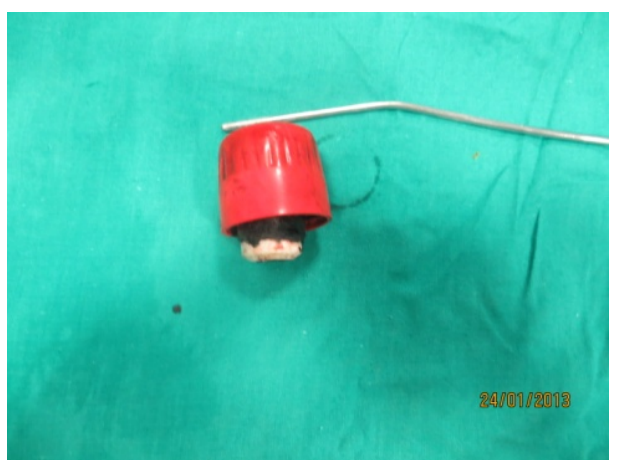

Figure 2. Photograph showing the front part of a red colored plastic torch removed from the vagina.

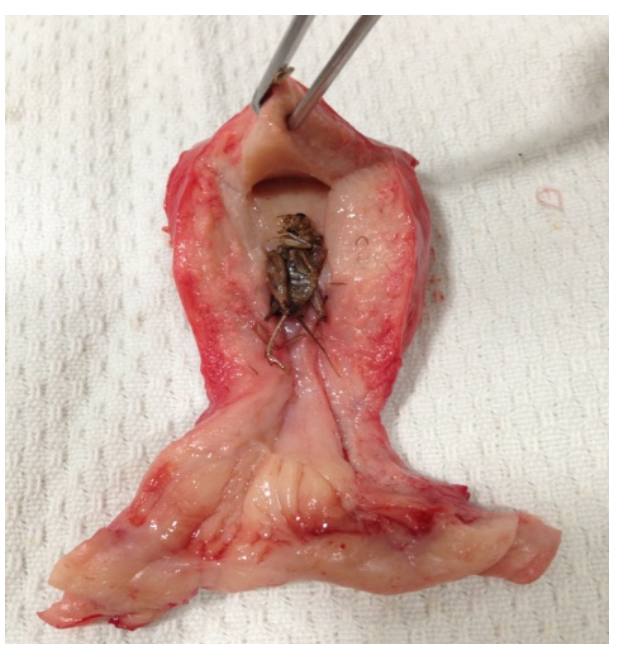

Figure 3. Photograph showing a dead cricket found on cutting the gross specimen of uterus within the uterine cavity. 
drug carriage is more common in international travelers [6]. Pessaries have been used for centuries in the management of uterine prolapse. Although surgery is the definitive treatment for severe uterine prolapse, pessarie can give satisfactory results in women who desire or need to avoid surgery. Innate objects like insects may move into the genital tract unnoticed, more often in old women with dementia and neglected prolapse.

Retained objects in the vagina cause mucosal irritation and discharge which following infection results in purulent malodorous discharge. Persistence of the foreign body causes granulation tissue formation eventually leading to adhesions, fibrosis and eventually stenosis of vagina. Diagnosis is based on detailed history, clinical and gynaecological examination. Use of bacteriological cultures, ultrasound examination [7] and X ray and other radiological assessment may be needed in few cases. In some patients with poor compliance or deeply impacted foreign bodies not amenable to diagnosis by other modalities, 3D multiplanar CT [8] scans may be necessary to help clinch the diagnosis.

Serious complications resulting due to foreign objects being impacted or displaced include local tissue trauma, bladder injury, bowel obstruction [9], peritoneal perforation and peritonitis [10], vesico-vaginal and rectovaginal fistulas [10]. Russell reported seeing patients with complications such as a rectovaginal fistula,vaginal cancer and chronic vaginitis [11]. Other complications are incarceration, ulceration and metaplasia, urosepsis and hydronephrosis [12]. Jain et al. reported two cases of vaginal cancer associated with pessary use [13].

\section{Conclusion}

Foreign objects in the genital tract are commonly encountered and the patient may not be aware of its presence. These objects may have been retained for a very long duration and may result in vaginal discharge or even lead to life-threatening complications. One should always exclude the presence of a foreign object in the genital tract in a patient presenting with these complaints especially among children. Early diagnosis can help in proper management and avoidance of such complications. Patients being provided medical aids such as pessaries and vaginal contraceptives should be encouraged to come for regular follow-up.

\section{Conflict of Interest}

There is no any conflict of interest among the Authors.

\section{References}

[1] Paradise, J.E. and Willis, E.D. (1985) Probability of Vaginal Foreign Body in Girls with General Complaints. American Journal of Diseases of Children, 139, 472-476.

[2] Gupta, N., Singh, N., Misra, R., Mittal, S. Roberge, R.J., Keller, C. and Garfinkel, M. (2001) Vaginal Pessaryn-Induced Mechanical Bowel Obstruction. The Journal of Emergency Medicine, 20, 367-370. http://dx.doi.org/10.1016/S0736-4679(01)00313-4

[3] Gupta, N., Singh, N., Misra, R. and Mittalan, S. (2007) Unusual Foreign Body Incarcerated in the Uterus. Journal of the Turkish German Gynecological Association, 8, 208-210.

[4] Closson, F.T. and Lichenstein, R. (2013) Vaginal Foreign Bodies and Child Sexual Abuse: An Important Consideration. Western Journal of Emergency Medicine, 14, 437-439. http://dx.doi.org/10.5811/westjem.2013.1.13347

[5] Yazicioglu, H.F., Yasar, L. and Dulger, O. (2004) Hysteroscopic Removal of a Foreign Body from the Subvesical Space. International Journal of Gynecology \& Obstetrics, 86, 48-49. http://dx.doi.org/10.1016/j.jjgo.2004.04.031

[6] Benjamin, F., Guilaume, A.J., Chao, L.P. and Jean, G.A. (1994) Vaginal Smuggling of Illicit Drug: A Case Requiring Obstetric Forceps for Removal of Drug Container. American Journal of Obstetrics and Gynecology, 171, 1385-1387. http://dx.doi.org/10.1016/0002-9378(94)90168-6

[7] Caspi, B., Zalel, Y., Elchalal, U. and Katz, Z. (1994) Sonographic Detection of Vaginal Foreign Bodies. Journal of Ultrasound Medicine, 13, 236-237.

[8] Mausner, E.V., Yitta, S., Slywotzky, C.M. and Bennett, G.L. (2011) Commonly Encountered Foreign Bodies and Devices in the Female Pelvis: MDCT Appearances. American Journal of Roentgenology, 196, W461-W470.

[9] Puneet, Khanna A, Khanna AK. (2002) Intravaginal Foreign Body-A Rare Cause of Large Bowel Obstruction. Journal of Indian Medical Association, 100, 671.

[10] O’Hanlon, K.A. and Westphal, L.M. (1995) First Report of a Vaginal Foreign Body Perforation into the Peritoneum. American Journal of Obstetrics and Gynecology, 173, 962-964. http://dx.doi.org/10.1016/0002-9378(95)90379-8 
[11] Russell, J.K. (1961) The Dangerous Vaginal Pessary. BMJ, 2, 1595-1597. http://dx.doi.org/10.1136/bmj.2.5267.1595

[12] Duncan, L.E., Foltzer, M., O’Hearn, M., et al. (1997) Unilateral Hydronephrosis, Pyelonephritis, and Bacteremia Caused by a Neglected Vaginal Ring Pessary. Journal of the American Geriatrics Society, 45, 1413-1414.

[13] Jain, A., Majoko, F. and Freites, O. (2006) How Innocent Is the Vaginal Pessary? Two Cases of Vaginal Cancer Associated with Pessary Use. Journal of Obstetrics \& Gynaecology, 26, 829-830. http://dx.doi.org/10.1080/01443610600994825 